\title{
Generalized Semipre Regular Closed Sets in Intuitionistic Fuzzy Topological Spaces
}

\author{
K. Ramesh \\ MPhil Scholar., Department of Mathematics, \\ NGM College, Pollachi-642001, Tamil Nadu, \\ India.
}

\author{
M. Thirumalaiswamy \\ Asso. Prof., Department of Mathematics, \\ NGM College, Pollachi-642001, Tamil Nadu, \\ India.
}

\begin{abstract}
In this paper, we introduce the notion of an intuitionistic fuzzy generalized semipre regular closed sets and intuitionistic fuzzy generalized semipre regular open sets and study some of its properties in Intuitionistic fuzzy topological spaces.
\end{abstract}

Keywords: Intuitionistic fuzzy topology, intuitionistic fuzzy generalized semipre regular closed sets, intuitionistic fuzzy generalized semipre regular open sets and intuitionistic fuzzy points.

2010 Mathematics Subject Classification : 54A40, 03F55.

\section{INTRODUCTION}

In 1965, Zadeh [14] introduced fuzzy sets and in 1968, Chang [2] introduced fuzzy topology. After the introduction of fuzzy set and fuzzy topology, several authors were conducted on the generalization of these notions. In 1986, the notion of intuitionistic fuzzy sets was introduced by Atanassov [1] as a generalization of fuzzy sets. In 1997, Coker [3] introduced the concept of intuitionistic fuzzy topological spaces. In this paper, we introduce intuitionistic fuzzy generalized semipre regular closed sets and intuitionistic fuzzy generalized semipre regular open sets in intuitionistic fuzzy topological space. We study some of its properties in intuitionistic fuzzy topological spaces.

\section{PRELIMINARIES}

Throughout this paper, $(\mathrm{X}, \tau)$ or $\mathrm{X}$ denotes the intuitionistic fuzzy topological spaces (briefly IFTS). For a subset $\mathrm{A}$ of $\mathrm{X}$, the closure, the interior and the complement of $\mathrm{A}$ are denoted by $\operatorname{cl}(\mathrm{A}), \operatorname{int}(\mathrm{A})$ and $\mathrm{A}^{\mathrm{c}}$ respectively. We recall some basic definitions that are used in the sequel.

Definition 2.1: [1] Let $X$ be a non-empty fixed set. An intuitionistic fuzzy set (IFS in short) $\mathrm{A}$ in $\mathrm{X}$ is an object having the form

$$
A=\left\{\left\langle x, \mu_{A}(x), v_{A}(x)\right\rangle / x \in X\right\}
$$

where the functions $\mu_{\mathrm{A}}: \mathrm{X} \rightarrow[0,1]$ and $v_{\mathrm{A}}: \mathrm{X} \rightarrow[0,1]$ denote the degree of membership (namely $\mu_{\mathrm{A}}(\mathrm{x})$ ) and the degree of non-membership (namely $v_{\mathrm{A}}(\mathrm{x})$ ) of each element $\mathrm{x} \in \mathrm{X}$ to the set $\mathrm{A}$, respectively, and $0 \leq \mu_{\mathrm{A}}(\mathrm{x})+v_{\mathrm{A}}(\mathrm{x}) \leq 1$ for each $\mathrm{x} \in \mathrm{X}$. Denote by $\operatorname{IFS}(\mathrm{X})$, the set of all intuitionistic fuzzy sets in $X$.

Definition 2.2: [1] Let A and $B$ be IFSs of the form $\mathrm{A}=\left\{\left\langle\mathrm{x}, \quad \mu_{\mathrm{A}}(\mathrm{x}), \quad v_{\mathrm{A}}(\mathrm{x})\right\rangle / \quad \mathrm{x} \in \mathrm{X}\right\}$ and $\mathrm{B}=$ $\left\{\left\langle\mathrm{x}, \mu_{\mathrm{B}}(\mathrm{x}), v_{\mathrm{B}}(\mathrm{x})\right\rangle / \mathrm{x} \in \mathrm{X}\right\}$. Then

(i) $\mathrm{A} \subseteq \mathrm{B}$ if and only if $\mu_{\mathrm{A}}(\mathrm{x}) \leq \mu_{\mathrm{B}}(\mathrm{x})$ and $v_{\mathrm{A}}(\mathrm{x}) \geq$ $v_{\mathrm{B}}(\mathrm{X})$ for all $\mathrm{x} \in \mathrm{X}$,

(ii) $\mathrm{A}=\mathrm{B}$ if and only if $\mathrm{A} \subseteq \mathrm{B}$ and $\mathrm{B} \subseteq \mathrm{A}$,

(iii) $\mathrm{A}^{\mathrm{c}}=\left\{\left\langle\mathrm{x}, v_{\mathrm{A}}(\mathrm{x}), \mu_{\mathrm{A}}(\mathrm{x})\right\rangle / \mathrm{x} \in \mathrm{X}\right\}$,

(iv) $\mathrm{A} \cap \mathrm{B}=\left\{\left\langle\mathrm{x}, \mu_{\mathrm{A}}(\mathrm{x}) \wedge \mu_{\mathrm{B}}(\mathrm{x}), v_{\mathrm{A}}(\mathrm{x}) \vee v_{\mathrm{B}}(\mathrm{x})\right\rangle / \mathrm{x} \in\right.$ $\mathrm{X}$ \},

www.ijcat.com (v) $A \cup B=\left\{\left\langle x, \mu_{A}(x) \vee \mu_{B}(x), v_{A}(x) \wedge v_{B}(x)\right\rangle / x \in\right.$ $\mathrm{X}\}$.

For the sake of simplicity, we shall use the notation $\mathrm{A}=$ $\left\langle\mathrm{x}, \mu_{\mathrm{A}}, v_{\mathrm{A}}\right\rangle$ instead of $\mathrm{A}=\left\{\left\langle\mathrm{x}, \mu_{\mathrm{A}}(\mathrm{x}), v_{\mathrm{A}}(\mathrm{x})\right\rangle / \mathrm{x} \in \mathrm{X}\right\}$.

Definition 2.3: [3] An intuitionistic fuzzy topology (IFT in short) on $\mathrm{X}$ is a family $\tau$ of IFSs in $\mathrm{X}$ satisfying the following axioms:

(i) $0_{\sim}, 1_{\sim} \in \tau$,

(ii) $\mathrm{G}_{1} \cap \mathrm{G}_{2} \in \tau$, for any $\mathrm{G}_{1}, \mathrm{G}_{2} \in \tau$,

(iii) $\cup \mathrm{G}_{\mathrm{i}} \in \tau$ for any family $\left\{\mathrm{G}_{\mathrm{i}} / \mathrm{i} \in \mathrm{J}\right\} \subseteq \tau$.

In this case the pair $(\mathrm{X}, \tau)$ is called an intuitionistic fuzzy topological space (IFTS in short) and any IFS in $\tau$ is known as an intuitionistic fuzzy open set (IFOS in short) in X. The complement $\mathrm{A}^{\mathrm{c}}$ of an IFOS $\mathrm{A}$ in an IFTS $(\mathrm{X}, \tau)$ is called an intuitionistic fuzzy closed set (IFCS in short) in X.

Definition 2.4: [3] Let $(X, \tau)$ be an IFTS and $A=$ $\left\langle\mathrm{x}, \mu_{\mathrm{A}}, v_{\mathrm{A}}\right\rangle$ be an IFS in X. Then the intuitionistic fuzzy interior and an intuitionistic fuzzy closure are defined by $\operatorname{int}(\mathrm{A})=\mathrm{U}\{\mathrm{G} / \mathrm{G}$ is an IFOS in $\mathrm{X}$ and $\mathrm{G} \subseteq \mathrm{A}\}$, $\operatorname{cl}(\mathrm{A})=\cap\{\mathrm{K} / \mathrm{K}$ is an IFCS in $\mathrm{X}$ and $\mathrm{A} \subseteq \mathrm{K}\}$.

Definition 2.5: [4] An IFS A of an IFTS (X, $\tau)$ is an

(i) intuitionistic fuzzy regular closed set (IFRCS in short) if $\mathrm{A}=\operatorname{cl}(\operatorname{int}(\mathrm{A}))$,

(ii) intuitionistic fuzzy regular open set (IFROS in short) if $\mathrm{A}=\operatorname{int}(\mathrm{cl}(\mathrm{A}))$,

(iii) intuitionistic fuzzy semiclosed set (IFSCS in short) if $\operatorname{int}(\mathrm{cl}(\mathrm{A})) \subseteq \mathrm{A}$,

(iv) intuitionistic fuzzy semiopen set (IFSOS in short) if $\mathrm{A} \subseteq \operatorname{cl}(\operatorname{int}(\mathrm{A}))$

(v) intuitionistic fuzzy preclosed set (IFPCS in short) if $\operatorname{cl}(\operatorname{int}(\mathrm{A})) \subseteq \mathrm{A}$,

(vi) intuitionistic fuzzy preopen set (IFPOS in short) if $\mathrm{A} \subseteq \operatorname{int}(\mathrm{cl}(\mathrm{A}))$

Definition 2.6: [13] An IFS A of an IFTS (X, $\tau)$ is an 
(i) intuitionistic fuzzy semipre closed set (IFSPCS in short) if there exists an IFPCS B such that $\operatorname{int}(\mathrm{B}) \subseteq \mathrm{A} \subseteq \mathrm{B}$,

(ii) intuitionistic fuzzy semipre open set (IFSPOS in short) if there exists an IFPOS $B$ such that $\mathrm{B} \subseteq \mathrm{A} \subseteq \mathrm{cl}(\mathrm{B})$.

Definition 2.7: [6] An IFS A is an IFTS $(X, \tau)$ is said to be an intuitionistic fuzzy generalized semipre closed set (IFGSPCS) if $\operatorname{spcl}(\mathrm{A}) \subseteq \mathrm{U}$ whenever $\mathrm{A} \subseteq \mathrm{U}$ and $\mathrm{U}$ is an IFSOS in $(\mathrm{X}, \tau)$. An IFS A of an IFTS $(\mathrm{X}, \tau)$ is called an intuitionistic fuzzy generalized semipre open set (IFGSPOS in short) if $\mathrm{A}^{\mathrm{c}}$ is an IFGSPCS in $(\mathrm{X}, \tau)$.

Definition 2.8: [12] An IFS A in an $\operatorname{IFTS}(X, \tau)$ is said to be an intuitionistic fuzzy semipre generalized closed set (IFSPGCS for short) if $\operatorname{spcl}(\mathrm{A}) \subseteq \mathrm{U}$ whenever $\mathrm{A} \subseteq \mathrm{U}$ and $\mathrm{U}$ is an IFSOS in $(\mathrm{X}, \tau)$.

Every IFCS, IFSCS, IFRCS, IFPCS, IFSPCS, is an IFSPGCS but the converses are not true in general.

Definition 2.9: [11] The complement $A^{c}$ of an IFSPGCS A in an IFTS $(\mathrm{X}, \tau)$ is called an intuitionistic fuzzy semipre generalized open set (IFSPGOS for short) in $\mathrm{X}$.

Definition 2.10: [6] Let A be an IFS in an IFTS $(\mathrm{X}, \tau)$. Then

(i) spint (A) $=U\{G / G$ is an IFSPOS in $X$ and $G \subseteq A\}$, (ii) $\operatorname{spcl}(\mathrm{A})=\cap\{\mathrm{K} / \mathrm{K}$ is an IFSPCS in $\mathrm{X}$ and $\mathrm{A} \subseteq \mathrm{K}\}$.

Note that for any IFS $\mathrm{A}$ in $(\mathrm{X}, \tau)$, we have $\operatorname{spcl}\left(\mathrm{A}^{\mathrm{c}}\right)=$ $(\operatorname{spint}(\mathrm{A}))^{\mathrm{c}}$ and $\operatorname{spint}\left(\mathrm{A}^{\mathrm{c}}\right)=(\operatorname{spcl}(\mathrm{A}))^{\mathrm{c}}$.

Definition 2.11: Let A be an IFS in an IFTS $(X, \tau)$. Then

(i) intuitionistic fuzzy regular generalized closed set (IFRGCS for short) if $\operatorname{cl}(\mathrm{A}) \subseteq \mathrm{U}$ whenever $\mathrm{A} \subseteq \mathrm{U}$ and $U$ is an intuitionistic fuzzy regular open in $\mathrm{X}$ [8],

(ii) intuitionistic fuzzy generalized pre regular closed set (IFGPRCS for short) if $\operatorname{pcl}(\mathrm{A}) \subseteq \mathrm{U}$ whenever $\mathrm{A} \subseteq \mathrm{U}$ and $\mathrm{U}$ is an intuitionistic fuzzy regular open in $\mathrm{X}[10]$,

(iii) intuitionistic fuzzy generalized pre closed set (IFGPCS for short) if $\operatorname{pcl}(\mathrm{A}) \subseteq \mathrm{U}$ whenever $\mathrm{A} \subseteq \mathrm{U}$ and $\mathrm{U}$ is an intuitionistic fuzzy open in $\mathrm{X}$ [5].

An IFS A of an IFTS $(\mathrm{X}, \tau)$ is called an intuitionistic fuzzy regular generalized open set, intuitionistic fuzzy generalized pre regular open set and intuitionistic fuzzy generalized pre open set (IFRGOS, IFGPROS and IFGPOS in short) if the complement $\mathrm{A}^{\mathrm{c}}$ is an IFRGCS, IFGPRCS and IFGPCS respectively.

Definition 2.12: [9] An IFTS $(X, \tau)$ is said to be an

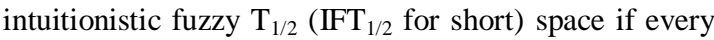
intuitionistic fuzzy generalized closed set in $\mathrm{X}$ is an intuitionistic fuzzy closed set in X.

Definition 2.13: [7] Let Let $\alpha, \beta \in[0,1]$ and $\alpha+\beta \leq 1$. An intuitionistic fuzzy point (IFP for short) $\mathrm{p}_{(\alpha, \beta)}$ of $\mathrm{X}$ is an IFS of $\mathrm{X}$ defined by

$$
p_{(\alpha, \beta)}(y)=\left\{\begin{array}{lll}
(\alpha, \beta) & \text { if } & y=x \\
(0,1) & \text { if } & y \neq x
\end{array}\right.
$$

\section{INTUITIONISTIC GENERALIZED REGULAR CLOSED SETS \\ FUZZY SEMIPRE}

In this section we have introduced intuitionistic fuzzy generalized semipre regular closed sets and have studied some of its properties.

Definition 3.1: An IFS A in an IFTS $(X, \tau)$ is said to be an intuitionistic fuzzy generalized semipre regular closed set (IFGSPRCS for short) if $\operatorname{spcl}(\mathrm{A}) \subseteq \mathrm{U}$ whenever $\mathrm{A} \subseteq \mathrm{U}$ and $\mathrm{U}$ is an IFROS in $(\mathrm{X}, \tau)$. The family of all IFGSPRCSs of an IFTS $(X, \tau)$ is denoted by IFGSPRC(X).

For the sake of simplicity, we shall use the notation $\mathrm{A}=$ $\langle\mathrm{x},(\mu, \mu),(v, v)\rangle$ instead of $\mathrm{A}=\left\langle\mathrm{x},\left(\mathrm{a} / \mu_{\mathrm{a}}, \mathrm{b} / \mu_{\mathrm{b}}\right),\left(\mathrm{a} / \mathrm{v}_{\mathrm{a}}\right.\right.$, $\left.\left.\mathrm{b} / v_{\mathrm{b}}\right)\right\rangle$ in all the examples used in this paper.

Example 3.2: Let $\mathrm{X}=\{\mathrm{a}, \mathrm{b}\}$ and $\mathrm{G}=\langle\mathrm{x},(0.5,0.4)$, $(0.5,0.6)\rangle$. Then $\tau=\left\{0_{\sim}, \mathrm{G}, 1_{\sim}\right\}$ is an IFT on $\mathrm{X}$ and the IFS $\mathrm{A}=\langle\mathrm{x},(0.4,0.2),(0.6,0.7)\rangle$ is an IFGSPRCS in $(\mathrm{X}, \tau)$.

Theorem 3.3: Every IFCS in $(X, \tau)$ is an IFGSPRCS in $(\mathrm{X}, \tau)$ but not conversely.

Proof: Let $A$ be an IFCS. Let $A \subseteq U$ and $U$ be an IFROS in $(\mathrm{X}, \tau)$. Then $\operatorname{spcl}(\mathrm{A}) \subseteq \operatorname{cl}(\mathrm{A})=\mathrm{A} \subseteq \mathrm{U}$, by hypothesis. Hence $\mathrm{A}$ is an IFGSPRCS in $(\mathrm{X}, \tau)$.

Example 3.4: In Example 3.2., the IFS $A=\langle x$, $(0.4,0.2),(0.6,0.7)\rangle$ is an IFGSPRCS but not an IFCS in $(\mathrm{X}, \tau)$.

Theorem 3.5: Every IFRGCS in $(X, \tau)$ is an IFGSPRCS in $(\mathrm{X}, \tau)$ but not conversely.

Proof: Let $\mathrm{A}$ be an IFRGCS. Let $\mathrm{A} \subseteq \mathrm{U}$ and $\mathrm{U}$ be an IFROS in $(\mathrm{X}, \tau)$. Then $\operatorname{spcl}(\mathrm{A}) \subseteq \operatorname{cl}(\mathrm{A}) \subseteq \mathrm{U}$, by hypothesis. Hence $\mathrm{A}$ is an IFGSPRCS in $(\mathrm{X}, \tau)$.

Example 3.6: Let $X=\{a, b\}$ and $G=\langle x,(0.5,0.4)$, $(0.5,0.6)\rangle$. Then $\tau=\left\{0_{\sim}, \mathrm{G}, 1_{\sim}\right\}$ is an IFT on $\mathrm{X}$ and the IFS $\mathrm{A}=\langle\mathrm{x},(0.4,0.2),(0.6,0.7)\rangle$ is an IFGSPRCS in $(\mathrm{X}, \tau)$ but not an IFRGCS in $(\mathrm{X}, \tau)$.

Theorem 3.7: Every IFGPRCS in $(\mathrm{X}, \tau)$ is an IFGSPRCS in $(\mathrm{X}, \tau)$ but not conversely.

Proof: Let $A$ be an IFGPRCS and $A \subseteq U$, $U$ be an IFROS in $(\mathrm{X}, \tau)$. Then $\operatorname{spcl}(\mathrm{A}) \subseteq \operatorname{pcl}(\mathrm{A})$, since $\operatorname{pcl}(\mathrm{A}) \subseteq$ $\mathrm{U}$. We have $\operatorname{spcl}(\mathrm{A}) \subseteq \mathrm{U}$. Hence $\mathrm{A}$ is an IFGSPRCS in $(\mathrm{X}, \tau)$.

Example 3.8: Let $\mathrm{X}=\{\mathrm{a}, \mathrm{b}\}$ and $\mathrm{G}_{1}=\langle\mathrm{x},(0.7,0.8)$, $(0.3,0.2)\rangle, \mathrm{G}_{2}=\langle\mathrm{x},(0.2,0.1),(0.8,0.9)\rangle, \mathrm{G}_{3}=\langle\mathrm{x}$, $(0.5,0.6),(0.5,0.4)\rangle$ and $\mathrm{G}_{4}=\langle\mathrm{x},(0.6,0.7),(0.4,0.3)\rangle$. Then $\tau=\left\{0_{\sim}, G_{1}, G_{2}, G_{3}, G_{4}, 1_{\sim}\right\}$ is an IFT on X and the IFS $\mathrm{A}=\langle\mathrm{x},(0.7,0.8),(0.3,0.2)\rangle$ is an IFGSPRCS but not an IFGPRCS in $(\mathrm{X}, \tau)$.

Theorem 3.9: Every IFPCS in $(X, \tau)$ is an IFGSPRCS in $(\mathrm{X}, \tau)$ but not conversely. 
Proof: Let $A$ be an IFPCS in $(X, \tau)$ and let $A \subseteq U, U$ be an IFROS in $(\mathrm{X}, \tau)$. Then $\operatorname{spcl}(\mathrm{A}) \subseteq \operatorname{pcl}(\mathrm{A})=\mathrm{A} \subseteq \mathrm{U}$, by hypothesis. Hence is an IFGSPRCS in $(\mathrm{X}, \tau)$.

Example 3.10: Let $X=\{a, b\}$ and $G=\langle x,(0.3,0.2)$, $(0.6,0.6)\rangle$. Then $\tau=\left\{0_{\sim}, \mathrm{G}, 1_{\sim}\right\}$ is an IFT on $\mathrm{X}$ and the IFS $\mathrm{A}=\langle\mathrm{x},(0.3,0.2),(0.6,0.6)\rangle$ is an IFGSPRCS in $(\mathrm{X}, \tau)$ but not an IFPCS in $(\mathrm{X}, \tau)$.

Theorem 3.11: Every IFGPCS in $(X, \tau)$ is an IFGSPRCS in $(\mathrm{X}, \tau)$ but not conversely.

Proof: Let $A$ be an IFGPCS in $(X, \tau)$. Let $A \subseteq U$ and $\mathrm{U}$ be an IFROS in $(X, \tau)$. Since every IFROS in $(X, \tau)$ is an IFOS in $(\mathrm{X}, \tau)$. Then $\operatorname{spcl}(\mathrm{A}) \subseteq \operatorname{pcl}(\mathrm{A}) \subseteq \mathrm{U}$. Hence is an IFGSPRCS in $(\mathrm{X}, \tau)$.

Example 3.12: Let $X=\{a, b\}$ and $G=\langle x,(0.3,0.6)$, $(0.7,0.4)\rangle$. Then $\tau=\left\{0_{\sim}, \mathrm{G}, 1_{\sim}\right\}$ is an IFT on $\mathrm{X}$ and the IFS $\mathrm{A}=\langle\mathrm{x},(0.3,0.6),(0.7,0.4)\rangle$ is an IFGSPRCS in $(\mathrm{X}, \tau)$ but not an IFGPCS in $(\mathrm{X}, \tau)$.

Theorem 3.13: Every IFRCS in $(X, \tau)$ is an IFGSPRCS in $(\mathrm{X}, \tau)$ but not conversely.

Proof: Let A be an IFRCS in $(X, \tau)$. Since every IFRCS is an IFCS, by Theorem 3.3., $\mathrm{A}$ is an IFGSPRCS in $(\mathrm{X}, \tau)$.

Example 3.14: In Example 3.2., the IFS $A=\langle x$, $(0.4,0.2),(0.6,0.7)\rangle$ is an IFGSPRCS but not an IFRCS in $(\mathrm{X}, \tau)$.

Theorem 3.15: Every IFSCS in $(X, \tau)$ is an IFGSPRCS in $(\mathrm{X}, \tau)$ but not conversely.

Proof: Let $A$ be an IFSCS in $(X, \tau)$. Let $A \subseteq U$ and $\mathrm{U}$ be an IFROS in $(\mathrm{X}, \tau)$. Since $\operatorname{spcl}(\mathrm{A}) \subseteq \operatorname{scl}(\mathrm{A})=\mathrm{A} \subseteq$ $\mathrm{U}$. Hence $\operatorname{spcl}(\mathrm{A}) \subseteq \mathrm{U}$. Therefore $\mathrm{A}$ is an IFGSPRCS in $(\mathrm{X}, \tau)$.

Example 3.16: In Example 3.2., the IFS $A=\langle x$, $(0.4,0.2),(0.6,0.7)\rangle$ is an IFGSPRCS but not an IFSCS in $(X, \tau)$.

Theorem 3.17: Every IFSPCS in $(X, \tau)$ is an IFGSPRCS in $(\mathrm{X}, \tau)$ but not conversely.

Proof: Let $\mathrm{A}$ be an IFSPCS and $\mathrm{A} \subseteq \mathrm{U}, \mathrm{U}$ be an IFROS in $(\mathrm{X}, \tau)$. Then since $\operatorname{spcl}(\mathrm{A})=\mathrm{A}$ and $\mathrm{A} \subseteq \mathrm{U}$, we have $\operatorname{spcl}(\mathrm{A}) \subseteq \mathrm{U}$. Hence $\mathrm{A}$ is an IFGSPRCS in $(\mathrm{X}, \tau)$.

Example 3.18: Let $X=\{a, b\}$ and $G_{1}=\langle x$, $(0.7,0.8),(0.3,0.2)\rangle, \mathrm{G}_{2}=\langle\mathrm{x},(0.2,0.1),(0.8,0.9)\rangle, \mathrm{G}_{3}=$ $\langle\mathrm{x},(0.5,0.6),(0.5,0.4)\rangle$ and $\mathrm{G}_{4}=\langle\mathrm{x},(0.6,0.7)$, $(0.4,0.3)\rangle$. Then $\tau=\left\{0_{\sim}, \mathrm{G}_{1}, \mathrm{G}_{2}, \mathrm{G}_{3}, \mathrm{G}_{4}, 1_{\sim}\right\}$ is an IFT on $\mathrm{X}$ and the IFS $\mathrm{A}=\langle\mathrm{x},(0.9,0.6),(0.1,0.4)\rangle$ is an IFGSPRCS but not an IFSPCS in $(X, \tau)$.

Theorem 3.19: Every IFSPGCS in $(X, \tau)$ is an IFGSPRCS in $(\mathrm{X}, \tau)$ but not conversely.

Proof: Let $A$ be an IFSPGCS in $(X, \tau)$. Let $A \subseteq U$ and $U$ is an IFROS in $(X, \tau)$. Since every IFROS in
$(\mathrm{X}, \tau)$ is an IFOS in $(\mathrm{X}, \tau)$ and every IFOS in $(\mathrm{X}, \tau)$ is an IFSOS in $(\mathrm{X}, \tau)$. We have $\operatorname{spcl}(\mathrm{A}) \subseteq \mathrm{U}$, by hypothesis. Hence $A$ is an IFGSPRCS in $(X, \tau)$.

Example 3.20: In Example 3.12., the IFS $A=\langle x$, $(0.3,0.6),(0.7,0.4)\rangle$ is an IFGSPRCS in $(X, \tau)$ but not an IFSPGCS in $(\mathrm{X}, \tau)$.

Theorem 3.21: Every IFGSPCS in $(X, \tau)$ is an IFGSPRCS in $(\mathrm{X}, \tau)$ but not conversely.

Proof: Let $A$ be an IFGSPCS in $(X, \tau)$. Let $A \subseteq U$ and $U$ is an IFROS in $(X, \tau)$. Since every IFROS in $(\mathrm{X}, \tau)$ is an IFOS in $(\mathrm{X}, \tau)$. We have $\operatorname{spcl}(\mathrm{A}) \subseteq \mathrm{U}$, by hypothesis. Hence A is an IFGSPRCS in $(\mathrm{X}, \tau)$.

Example 3.22: In Example 3.12., the IFS $A=\langle x$, $(0.3,0.6),(0.7,0.4)\rangle$ is an IFGSPRCS in $(X, \tau)$ but not an IFGSPCS in $(\mathrm{X}, \tau)$.

In the following diagram, we have provided the relation between various types of intuitionistic fuzzy closedness.

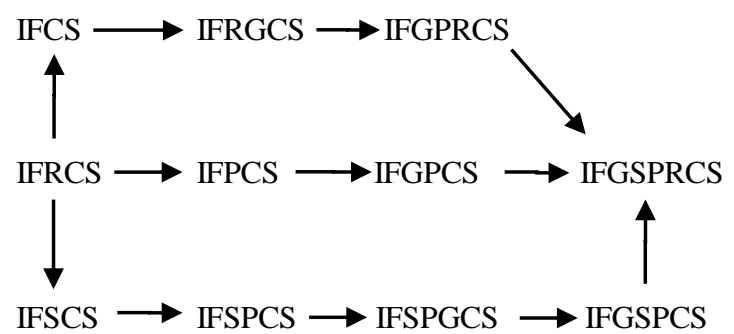

In this diagram by "A $\longrightarrow \mathrm{B}$ " we mean A implies B but not conversely.

Theorem 3.23: Let $(X, \tau)$ be an IFTS. Then for every $A \in \operatorname{IFGSPRC}(X)$ and for every IFS B $\in \operatorname{IFS}(X)$, $\mathrm{A} \subseteq \mathrm{B} \subseteq \operatorname{spcl}(\mathrm{A})$ implies $\mathrm{B} \in \operatorname{IFGSPRC}(\mathrm{X})$.

Proof: Let $\mathrm{B} \subseteq \mathrm{U}$ and $\mathrm{U}$ is an IFROS in $(\mathrm{X}, \tau)$. Then since $\mathrm{A} \subseteq \mathrm{B}, \mathrm{A} \subseteq \mathrm{U}$. Since $\mathrm{A}$ is an IFGSPRCS, it follows that $\operatorname{spcl}(\mathrm{A}) \subseteq \mathrm{U}$. Now $\mathrm{B} \subseteq \operatorname{spcl}(\mathrm{A})$ implies $\operatorname{spcl}(\mathrm{B}) \subseteq \operatorname{spcl}(\operatorname{spcl}(\mathrm{A}))=\operatorname{spcl}(\mathrm{A}) . \quad$ Thus, $\operatorname{spcl}(\mathrm{B}) \subseteq \mathrm{U}$. This proves that $\mathrm{B} \in \operatorname{IFGSPRC}(\mathrm{X})$.

Theorem 3.24: If $A$ is an IFROS and an $\operatorname{IFGSPRCS}$ in $(X, \tau)$, then A is an IFSPCS in $(X, \tau)$.

Proof: Since $A \subseteq A$ and $A$ is an IFROS in $(X, \tau)$, by hypothesis, $\operatorname{spcl}(\mathrm{A}) \subseteq \mathrm{A}$. But since $\mathrm{A} \subseteq \operatorname{spcl}(\mathrm{A})$. Therefore $\operatorname{spcl}(\mathrm{A})=\mathrm{A}$. Hence $\mathrm{A}$ is an IFSPCS in $(\mathrm{X}, \tau)$.

Theorem 3.25: Let $(X, \tau)$ be an IFTS. Then for every $\mathrm{A} \in \operatorname{IFSPC}(\mathrm{X})$ and for every IFS B in $\mathrm{X}$, int $(\mathrm{A}) \subseteq$ $\mathrm{B} \subseteq \mathrm{A} \Rightarrow \mathrm{B} \in \operatorname{IFGSPRC}(\mathrm{X})$

Proof: Let A be an IFSPCS in X. Then there exists an IFPCS, say $\mathrm{C}$ such that $\operatorname{int}(\mathrm{C}) \subseteq \mathrm{A} \subseteq \mathrm{C}$. By hypothesis, $\mathrm{B} \subseteq \mathrm{A}$. Therefore $\mathrm{B} \subseteq \mathrm{C}$. Since $\operatorname{int}(\mathrm{C}) \subseteq \mathrm{A}$, $\operatorname{int}(\mathrm{C}) \subseteq \operatorname{int}(\mathrm{A})$ and $\operatorname{int}(\mathrm{C}) \subseteq \mathrm{B}$. Thus $\operatorname{int}(\mathrm{C}) \subseteq \mathrm{B} \subseteq \mathrm{C}$ and by Definition 2.6., $\mathrm{B} \in \operatorname{IFSPC}(\mathrm{X})$. Hence by Theorem 3.17, B $\in$ IFGSPRC(X). 


\section{INTUITIONISTIC GENERALIZED REGULAR OPEN SETS}

\section{FUZZY} SEMIPRE

In this section we have introduced intuitionistic fuzzy generalized semipre regular open sets and have studied some of its properties.

Definition 4.1: An IFS $A$ is said to be an intuitionistic fuzzy generalized semipre regular open set (IFGSPROS for short) in $(\mathrm{X}, \tau)$ if the complement $\mathrm{A}^{\mathrm{c}}$ is an IFGSPRCS in X.

The family of all IFGSPROSs of an $\operatorname{IFTS}(\mathrm{X}, \tau)$ is denoted by IFGSPRO(X).

Theorem 4.2: Every IFOS, IFRGOS, IFGPROS, IFPOS, IFGPOS, IFROS, IFSOS, IFSPOS, IFSPGOS, IFGSPOS is an IFGSPROS but the converses are not true in general.

\section{Proof: Straight forward}

Example 4.3: Let $X=\{a, b\}$ and $G=\langle x,(0.5,0.4)$, $(0.5,0.6)\rangle$. Then $\tau=\left\{0_{\sim}, \mathrm{G}, 1_{\sim}\right\}$ is an IFT on $\mathrm{X}$ and the IFS $\mathrm{A}=\langle\mathrm{x},(0.6,0.7),(0.4,0.2)\rangle$ is an IFGSPROS in $(\mathrm{X}, \tau)$ but not an IFOS, IFSOS, IFROS, IFRGOS in $(\mathrm{X}, \tau)$

Example 4.4: Let $X=\{a, b\}$ and $G=\langle x,(0.3,0.6)$, $(0.7,0.4)\rangle$. Then $\tau=\left\{0_{\sim}, \mathrm{G}, 1_{\sim}\right\}$ is an IFT on $\mathrm{X}$ and the IFS $\mathrm{A}=\langle\mathrm{x},(0.7,0.4),(0.3,0.6)\rangle$ is an IFGSPROS in $(\mathrm{X}, \tau)$ but not an IFGPOS, IFSPGOS, IFGSPOS in $(\mathrm{X}, \tau)$.

Example 4.5: Let $X=\{a, b\}$ and $G_{1}=\langle x,(0.7,0.8)$, $(0.3,0.2)\rangle, \mathrm{G}_{2}=\langle\mathrm{x},(0.2,0.1),(0.8,0.9)\rangle, \mathrm{G}_{3}=\langle\mathrm{x}$, $(0.5,0.6),(0.5,0.4)\rangle$ and $\mathrm{G}_{4}=\langle\mathrm{x},(0.6,0.7),(0.4,0.3)\rangle$. Then $\tau=\left\{0_{\sim}, G_{1}, G_{2}, G_{3}, G_{4}, 1_{\sim}\right\}$ is an IFT on $X$ and the IFS $\mathrm{A}=\langle\mathrm{x},(0.3,0.2),(0.7,0.8)\rangle$ is an IFGSPROS but not an IFGPROS in $(\mathrm{X}, \tau)$.

Example 4.6: Let $X=\{a, b\}$ and $G=\langle x,(0.3,0.2)$, $(0.6,0.6)\rangle$. Then $\tau=\left\{0_{\sim}, \mathrm{G}, 1_{\sim}\right\}$ is an IFT on $\mathrm{X}$ and the IFS $\mathrm{A}=\langle\mathrm{x},(0.6,0.6),(0.3,0.2)\rangle$ is an IFGSPROS in $(\mathrm{X}, \tau)$ but not an IFPOS in $(\mathrm{X}, \tau)$.

Example 4.7: Let $X=\{a, b\}$ and $G_{1}=\langle x,(0.7,0.8)$, $(0.3,0.2)\rangle, \mathrm{G}_{2}=\langle\mathrm{x},(0.2,0.1),(0.8,0.9)\rangle, \mathrm{G}_{3}=\langle\mathrm{x}$, $(0.5,0.6),(0.5,0.4)\rangle$ and $\mathrm{G}_{4}=\langle\mathrm{x},(0.6,0.7),(0.4,0.3)\rangle$. Then $\tau=\left\{0_{\sim}, G_{1}, G_{2}, G_{3}, G_{4}, 1_{\sim}\right\}$ is an IFT on X and the IFS $\mathrm{A}=\langle\mathrm{x},(0.9,0.6),(0.1,0.4)\rangle$ is an IFGSPROS but not an IFSPOS in $(\mathrm{X}, \tau)$.

Theorem 4.8: Let $(X, \tau)$ be a IFTS. Then for every $\mathrm{A} \in \operatorname{IFGSPRO}(\mathrm{X})$ and for every $\mathrm{B} \in \mathrm{IFS}(\mathrm{X}), \operatorname{spint}(\mathrm{A}) \subseteq$ $\mathrm{B} \subseteq \mathrm{A}$ implies $\mathrm{B} \in \operatorname{IFGSPRO}(\mathrm{X})$.

Proof: Let A be any IFGSPROS of $X$ and $B$ be any IFS of $X$. By hypothesis spint $(A) \subseteq B \subseteq A$. Then $A^{c}$ is an IFGSPRCS in $\mathrm{X}$ and $\mathrm{A}^{\mathrm{c}} \subseteq \mathrm{B}^{\mathrm{c}} \subseteq \operatorname{spcl}\left(\mathrm{A}^{\mathrm{c}}\right)$. By Theorem 3.23., $\mathrm{B}^{\mathrm{c}}$ is an IFGSPRCS in $(\mathrm{X}, \tau)$. Therefore $\mathrm{B}$ is an IFGSPROS in $(\mathrm{X}, \tau)$. Hence $\mathrm{B} \in \operatorname{IFGSPRO}(\mathrm{X})$.

Theorem 4.9: An IFS A of an IFTS $(X, \tau)$ is an IFGSPROS in $(\mathrm{X}, \tau)$ if and only is $\mathrm{F} \subseteq \operatorname{spint}(\mathrm{A})$ whenever $\mathrm{F}$ is an IFRCS in $(\mathrm{X}, \tau)$ and $\mathrm{F} \subseteq \mathrm{A}$.

Proof: Necessity: Suppose A is an IFGSPROS in $(\mathrm{X}, \tau)$. Let $\mathrm{F}$ be an IFRCS in $(\mathrm{X}, \tau)$ such that $\mathrm{F} \subseteq \mathrm{A}$. Then $F^{c}$ is an IFROS and $A^{c} \subseteq F^{c}$. By hypothesis $A^{c}$ is an IFGSPRCS in $(\mathrm{X}, \tau)$, we have $\operatorname{spcl}\left(\mathrm{A}^{\mathrm{c}}\right) \subseteq \mathrm{F}^{\mathrm{c}}$. Therefore $\mathrm{F} \subseteq$ spint (A).

Sufficiency: Let $U$ be an IFROS in $(X, \tau)$ such that $\mathrm{A}^{\mathrm{c}} \subseteq \mathrm{U}$. By hypothesis, $\mathrm{U}^{\mathrm{c}} \subseteq$ spint $(\mathrm{A})$. Therefore $\operatorname{spcl}\left(\mathrm{A}^{\mathrm{c}}\right) \subseteq \mathrm{U}$ and $\mathrm{A}^{\mathrm{c}}$ is an IFGSPRCS in $(\mathrm{X}, \tau)$. Hence $\mathrm{A}$ is an IFGSPROS in $(\mathrm{X}, \tau)$.

Theorem 4.10: Let $(X, \tau)$ be an IFTS then for every $\mathrm{A} \in \operatorname{IFSPO}(\mathrm{X})$ and for every IFS $\mathrm{B}$ in $\mathrm{X}, \mathrm{A} \subseteq \mathrm{B} \subseteq$ cl(A) implies B $\in$ IFGSPRO(X).

Proof: Let $A$ be an IFSPOS in $X$. Then by Definition 2.6., there exists an IFPOS, say $\mathrm{C}$ such that $\mathrm{C}$ $\subseteq \mathrm{A} \subseteq \mathrm{cl}(\mathrm{C})$. By hypothesis $\mathrm{A} \subseteq \mathrm{B}$. Therefore $\mathrm{C} \subseteq \mathrm{B}$. Since $\mathrm{A} \subseteq \mathrm{cl}(\mathrm{C}), \operatorname{cl}(\mathrm{A}) \subseteq \mathrm{cl}(\mathrm{C})$ and $\mathrm{B} \subseteq \mathrm{cl}(\mathrm{C})$. Thus $\mathrm{C}$ $\subseteq \mathrm{B} \subseteq \operatorname{cl}(\mathrm{C})$.

This implies that $\mathrm{B}$ is an IFSPOS in $\mathrm{X}$. Then $\mathrm{By}$ Theorem 4.2., $\mathrm{B}$ is an IFGSPROS. That is $\mathrm{B} \in$ $\operatorname{IFGSPRO}(\mathrm{X})$.

\section{APPLICATIONS INTUITIONISTIC GENERALIZED REGULAR CLOSED SETS \\ OF FUZZY SEMIPRE}

In this section we have provided some applications of intuitionistic fuzzy generalized semipre regular closed sets in intuitionistic fuzzy topological spaces.

Definition 5.1: If every IFGSPRCS in $(X, \tau)$ is an IFSPCS in $(X, \tau)$, then the space can be called as an intuitionistic fuzzy semipre regular $T_{1 / 2}\left(\right.$ IFSPRT $_{1 / 2}$ for short) space.

Theorem 5.2: An IFTS $(X, \tau)$ is an $\operatorname{IFSPRT}_{1 / 2}$ space if and only if $\operatorname{IFSPOS}(\mathrm{X})=\operatorname{IFGSPRO}(\mathrm{X})$.

Proof: Necessity: Let $(\mathrm{X}, \tau)$ be an $\operatorname{IFSPRT}_{1 / 2}$ space. Let $\mathrm{A}$ be an IFGSPROS in $(\mathrm{X}, \tau)$. By hypothesis, $\mathrm{A}^{\mathrm{c}}$ is an IFGSPRCS in $(\mathrm{X}, \tau)$ and therefore $\mathrm{A}$ is an IFSPOS in $(\mathrm{X}, \tau)$. Hence $\operatorname{IFSPO}(\mathrm{X})=$ IFGSPRO(X).

Sufficiency: Let $\operatorname{IFSPO}(X, \tau)=\operatorname{IFGSPRO}(X, \tau)$. Let $A$ be an IFGSPRCS in $(X, \tau)$. Then $A^{c}$ is an IFSPOS in $(X, \tau)$. By hypothesis, $A^{c}$ is an IFSPOS in $(X, \tau)$ and therefore $A$ is an IFSPCS in $(X, \tau)$. Hence $(\mathrm{X}, \tau)$ is an $\operatorname{IFSPRT}_{1 / 2}$ space.

Remark 5.3: Not every IFSPRT $T_{1 / 2}$ space is an $\mathrm{IFT}_{1 / 2}$ space. This can be seen easily by the following example.

Example 5.4: Let $X=\{a, b\}$ and let $\tau=\left\{0_{\sim}, G, 1_{\sim}\right\}$ where $\mathrm{G}=\langle\mathrm{x},(0.5,0.4),(0.5,0.6)\rangle$. Then $\mathrm{X}$ is an IFSPRT $_{1 / 2}$ space but not an IFT I/2 $_{1 / 2}$ space. 
Theorem 5.5: For any IFS A in $(X, \tau)$ where $X$ is an $\operatorname{IFSPRT}_{1 / 2}$ space, $\mathrm{A} \in \mathrm{IFGSPRO}_{(\mathrm{X})}$ if and only if for every IFP $\mathrm{p}_{(\alpha, \beta)} \in \mathrm{A}$, there exists an IFGSPROS B in X such that $\mathrm{p}_{(\alpha, \beta)} \in \mathrm{B} \subseteq \mathrm{A}$.

Proof: Necessity: If $A \in \operatorname{IFGSPRO}(X)$, then we can take $\mathrm{B}=\mathrm{A}$ so that $\mathrm{p}_{(\alpha, \beta)} \in \mathrm{B} \subseteq \mathrm{A}$ for every $\operatorname{IFP} \mathrm{p}_{(\alpha, \beta)}$ $\in$ A.

Sufficiency: Let A be an IFS in $(X, \tau)$ and assume that there exists $\mathrm{B} \in \operatorname{IFGSPRO}(\mathrm{X})$ such that $\mathrm{p}_{(\alpha, \beta)} \in \mathrm{B} \subseteq$ A. Since $X$ is an IFSPRT $_{1 / 2}$ space, $B$ is an IFSPOS. Then $\mathrm{A}=\mathrm{U}_{\mathrm{p}(\alpha, \beta) \in \mathrm{A}}\{\mathrm{p}(\alpha, \beta)\} \subseteq \mathrm{U}_{\mathrm{p}(\alpha, \beta) \in \mathrm{A}} \mathrm{B} \subseteq \mathrm{A}$. Therefore $A=\bigcup_{p(\alpha, \beta) \in A} B$, which is an IFSPOS. Hence by Theorem 4.2., $\mathrm{A}$ is an IFGSPROS in $(\mathrm{X}, \tau)$.

Definition 5.6: $\operatorname{An} \operatorname{IFTS}(X, \tau)$ is said to be an intuitionistic fuzzy semipre regular $\mathrm{T}_{1 / 2}^{*}$ space (IFSPRT $^{*}{ }_{1 / 2}$ space for short) if every IFGSPRCS is an IFCS in $(X, \tau)$.

Remark 5.7: Every IFSPRT ${ }^{*}{ }_{1 / 2}$ space is an IFSPRT $_{1 / 2}$ space but not conversely.

Proof: Assume be an IFSPRT ${ }_{1 / 2}^{*}$ space. Let A be an IFGSPRCS in $(\mathrm{X}, \tau)$. By hypothesis, $\mathrm{A}$ is an IFCS. Since every IFCS is an IFSPCS, A is an IFSPCS in (X, $\tau)$. Hence $(X, \tau)$ is an $\operatorname{IFSPRT}_{1 / 2}$ space.

Example 5.8: Let $X=\{a, b\}$ and let $\tau=\left\{0_{\sim}, G, 1_{\sim}\right\}$ where $\mathrm{G}=\langle\mathrm{x},(0.5,0.4),(0.5,0.6)\rangle$. Then $(\mathrm{X}, \tau)$ is an IFSPRT $_{1 / 2}$ space but not an IFSPRT ${ }_{1 / 2}^{*}$ space, since the IFS $\mathrm{G}$ is an IFGSPRCS in $(\mathrm{X}, \tau)$ but not an IFCS in (X, $\tau)$, as $\mathrm{cl}(\mathrm{G})=\mathrm{G}^{\mathrm{c}} \neq \mathrm{G}$.

\section{References}

[1] K. Atanassov, Intuitionistic fuzzy sets, Fuzzy Sets and Systems, 20(1986), 87-96.

[2] C. L. Chang, Fuzzy topological spaces, J. Math. Anal. Appl. 24 (1968), 182- 190.

[3] D. Coker, An introduction to intuitionistic fuzzy topological space, Fuzzy Sets and Systems, 88(1997), 81-89.

[4] H. Gurcay, Es. A. Haydar and D. Coker, On fuzzy continuity in intuitionistic fuzzy topological spaces, J.Fuzzy Math.5 (2) (1997), 365-378.
[5] P. Rajarajeswari and L. Senthil Kumar, Generalized pre-closed sets in intuitionistic fuzzy topological spaces, International journal of Fuzzy Mathematics and Systems, 3(2011), 253-262.

[6] R. Santhi and D. Jayanthi, Intuitionistic fuzzy generalized semi-pre closed sets, Tripura Math.Soci., 2009, 61-72.

[7] Seok Jong Lee and Eun Pyo Lee, The category of intuitionistic fuzzy topological spaces, Bull. Korean Math. Soc. 37 (2000), No. 1, pp. 6376.

[8] S. S. Thakur and Rekha Chaturvedi, Regular generalized closed sets in Intuitionistic fuzzy topological spaces, Universitatea Din Bacau, studii Si Cercetari Seria: Mathematica, 16, 257-272 (2006).

[9] S. S. Thakur and Rekha Chaturvedi, Generalized continuity in intuitionistic fuzzy topological spaces, NIFS 12 (2006), 1, 38-44.

[10] S. S. Thakur and Jyoti Pandey Bajpai, On Intuitionistic fuzzy Gpr-closed sets, Fuzzy Inf. Eng, (2012)4: 425-444.

[11] M. Thirumalaiswamy and K. M. Arifmohammed, Semipre Generalized Open Sets and Applications of Semipre Generalized Closed Sets in Intuitionistic Fuzzy Topological Spaces, Inter. J. Math. Archive, 4(1), Jan2013, 1-5.

[12] M. Thirumalaiswamy and K. Ramesh, Semipre Generalized Closed Sets in Intuitionistic Fuzzy Topological Spaces, Inter. J. Math. Archive. 4(2), 2013, 1-5.

[13] Young Bae Jun and Seok- Zun Song, Intuitionistic fuzzy semi-pre open sets and Intuitionistic fuzzy semi-pre continuous mappings, Jour. of Appl. Math \& computing, 2005, 467-474.

[14] L. A. Zadeh, Fuzzy sets, Information and control, 8(1965)338-353. 